\title{
Amperometric Biosensor Based on Coimmobilization of Multiwalled Carbon Nanotubes and Horseradish Peroxidase-Gold Nanocluster Bioconjugates for Detecting $\mathrm{H}_{2} \mathrm{O}_{2}$
}

\author{
Qiong-Qiong Ren ${ }^{D},{ }^{1}$ Fen Yang, ${ }^{1}$ Wu Ren, ${ }^{1}$ Chang Wang, ${ }^{1}$ Wen-Shuai Jiang, \\ Zong-Ya Zhao, ${ }^{1}$ Jun Chen, ${ }^{2}$ Xuan-Yi Lu, ${ }^{1}$ and Yi Yu ${ }^{1}{ }^{1}$ \\ ${ }^{1}$ College of Medical Engineering, Xinxiang Medical University, China \\ ${ }^{2}$ School of Chemistry and Environmental Engineering, Wuhan Institute of Technology, China \\ Correspondence should be addressed to Yi Yu; xxmu2010yy@163.com
}

Received 19 January 2020; Revised 2 June 2020; Accepted 29 June 2020; Published 11 July 2020

Academic Editor: Bhanu P. S. Chauhan

Copyright (c) 2020 Qiong-Qiong Ren et al. This is an open access article distributed under the Creative Commons Attribution License, which permits unrestricted use, distribution, and reproduction in any medium, provided the original work is properly cited.

\begin{abstract}
An enzyme-based amperometric biosensor was fabricated for detecting hydrogen peroxide $\left(\mathrm{H}_{2} \mathrm{O}_{2}\right)$. Horseradish peroxidase (HRP) was modified using functionalized fluorescent gold nanoclusters (AuNCs) via biomineralization. HRP-AuNCs were successfully immobilized on multiwalled carbon nanotube- (MWCNT-) coated carbon fiber ultramicroelectrodes (CFUMEs). The AuNCs, which act as molecular electric wires, effectively promote the electron transfer between the enzyme active center and the electrode. Additionally, the HRP conjugated with the AuNCs retains its biological activity, which enables the catalytic reaction of $\mathrm{H}_{2} \mathrm{O}_{2}$. The HRP-AuNCs/MWCNTs/CFUMEs have been proven as excellent amperometric sensors for $\mathrm{H}_{2} \mathrm{O}_{2}$. The sensitivity of the $\mathrm{H}_{2} \mathrm{O}_{2}$ biosensor is $3.0 \times 10^{-4} \mathrm{~A} / \mathrm{M}$, and the detection limit is estimated to be $443 \mathrm{nM}$. Furthermore, the biosensor exhibited long-term stability and good reproducibility. Moreover, the biosensor has been tested by determining the $\mathrm{H}_{2} \mathrm{O}_{2}$ concentration in calf serum samples.
\end{abstract}

\section{Introduction}

Enzyme biosensors having both high sensitivity and specificity in amperometric measurement have received much attention in recent years [1]. Improving the stability of the electrode in long time detection has always been an important subject of research in the design and fabrication of enzyme biosensors [2,3]. However, the redox centers of the enzyme are embedded deeply because they are large and complex, making the electron exchange with the electrode surfaces difficult $[4,5]$. Mediators have been reported to improve electron exchange between enzymes and the electrode surface $[6,7]$. Therefore, the best result is to produce a direct electron transfer between enzymes and electrodes, which would help understand the nature of redox behaviors of enzymes and progress high performance without a mediator as well [8]. Effective electrical communication between the redox center of the enzyme and the electrode, which can provide an efficient and stable environment for the enzyme, is the key to constructing excellent biosensors based on the enzyme. In order to ensure high enzyme activity and enhance the electron transducer, various materials have been studied [9]. Among them, Au nanoparticles have been extensively used to fabricate enzyme sensors; this is because it can help transfer the electrons between the active center of the enzyme and the electrode, via concatenating the amino groups of the enzyme and the electrode $[10,11]$. In addition, the Au nanoparticle-conjugated enzyme can keep its high enzymatic activity. Okawa et al. [12] have immobilized horseradish peroxidase (HRP) on Au nanoparticles by dissolving HRP in Au nanoparticle dispersion for the construction of a hydrogen peroxide $\left(\mathrm{H}_{2} \mathrm{O}_{2}\right)$ biosensor. However, the binding force between HRP and Au nanoparticles due to the mixture is relatively smaller than HRP-AuNC bioconjugates, which may result in reduction of the sensor stability. Wen et al. [13] have reported a hydrogen peroxide sensor using 
fluorescent enzyme-AuNCs by means of a biomineralization process. HRP was used as the functional model template. HRP-AuNC bioconjugates were formed at physiological conditions by the direct synthesis of fluorescent gold nanoclusters (AuNCs). After the synthetic reaction, HRP retains its biologic activity to catalyze $\mathrm{H}_{2} \mathrm{O}_{2}$. However, measurements using fluorescent AuNCs are difficult for in vivo real-time and dynamic detection of $\mathrm{H}_{2} \mathrm{O}_{2}$ because they are irreversible and can only reflect the transient concentration. In contrast, electrochemical techniques, which capture the electron transfer between $\mathrm{HRP}$ and $\mathrm{H}_{2} \mathrm{O}_{2}$, using the AuNCs acting as a molecular electric wire, are more suitable for in vivo $\mathrm{H}_{2} \mathrm{O}_{2}$ measurement because of their simplicity, rapidity, and label-free detection capability, which can realize continuous monitoring. Thus, the construction of a direct electron transfer-based biosensor using HRP-AuNC bioconjugates can be useful for in vivo $\mathrm{H}_{2} \mathrm{O}_{2}$ detection.

In this study, the HRP enzyme biosensor is constructed by immobilizing multiwalled carbon nanotubes (MWCNTs) and HRP-AuNCs on the surface of carbon fiber ultramicroelectrodes (CFUMEs) for detecting $\mathrm{H}_{2} \mathrm{O}_{2}$. MWCNTs could effectively relieve surface fouling of electrodes by biomacromolecules and increase the sensitivity of electrodes by enlarging the surface area [14]. The HRP-AuNCs/MWCNTs/CFUMEs present high sensitivity and selectivity. The sensor is tested by measuring $\mathrm{H}_{2} \mathrm{O}_{2}$ in the serum solution.

\section{Materials and Methods}

2.1. Chemicals and Materials. HRP, glucose (GLU), glutathione (GSH), dopamine (DA), ascorbic acid (AA), glycine (Gly), and hexadecyltrimethylammonium bromide (CTAB) were purchased from Aladdin (Shanghai, China). Multiwalled carbon nanotubes (purity $>97 \mathrm{wt} \%$, outer diameter of $7-15 \mathrm{~nm}$, and length of $5 \mu \mathrm{m}$ ) were bought from Nanoport (Shenzhen, China). $\mathrm{H}_{2} \mathrm{O}_{2}$ standard solution (10 wt\%) was procured from the Beijing Beina Chuanglian Biotechnology Research Institute. Carbon fiber (diameter $7 \mu \mathrm{m}$ ) was purchased from Goodfellow Co. (Oxford, UK). Hydrogen tetrachloroaurate(III) trihydrate $\left(\mathrm{HAuCl}_{4} \cdot 3 \mathrm{H}_{2} \mathrm{O}\right)$ and all other reagents were purchased from Sinopharm (Shanghai, China). Deionized water was used to prepare all solutions in the experiments.

2.2. Synthesis of HRP-AuNCs. The HRP-AuNCs were synthesized according to previous reports [13]. In brief, aqua regia was used to wash all glassware. Then, the glassware was rinsed with deionized water. In addition, $1 \mathrm{~mL} \mathrm{HAuCl}_{4}$ solution $(3 \mathrm{mM})$ was added to $1 \mathrm{~mL}$ HRP solution $(10 \mathrm{mg} / \mathrm{mL})$ under vigorous shaking at $37^{\circ} \mathrm{C}$. The $\mathrm{pH}$ was adjusted above 12 by $1 \mathrm{M} \mathrm{NaOH}$ solution. The reaction continued for $12 \mathrm{~h}$ at $37^{\circ} \mathrm{C}$ under continuous shaking. During this reaction process, the color of the solution changed from reddish brown to blackish green. The final solution presented red fluorescence emission, which indicates the synthesis of AuNCs. Then, the formation of the HRP-AuNCs was also confirmed using a transmission electron microscope (as shown in Supplementary Figure 1).
2.3. Fabrication and Modification of CFUMEs. The CFUMEs were fabricated as in our previous report [15]. The carbon fiber ( $7 \mu \mathrm{m}$ diameter) was sealed in a spiculate glass capillary tip on a flame and exposed approximate $300 \mu \mathrm{m}$ long. The other end of carbon fiber was pasted on a copper wire via conducting silver paste. The copper wire enveloped the end of the glass capillary without sharpening by epoxy. The CFUMEs were ultrasonically cleaned and electrochemically activated before modification. The electroactivation voltage was between 0 and $+1.2 \mathrm{~V}$ in $0.01 \mathrm{M}$ phosphate buffer solution (PBS) by cyclic voltammetry.

The MWCNT turbid liquid $(3 \mathrm{mg} / \mathrm{mL}$, in $10 \mathrm{mg} / \mathrm{mL}$ CTAB solution) was obtained by an ultrasonic bath for $1 \mathrm{~h}$. The CFUME was dipped in the black suspension $(0.5 \mathrm{~mL})$ and placed in an $80^{\circ} \mathrm{C}$ oven until the solution was dried up. The HRP-AuNCs were fabricated on the electrode by soaking MWCNTs/CFUMEs in the above prepared HRP-AuNC solutions for $12 \mathrm{~h}$ at $4^{\circ} \mathrm{C}$.

2.4. Electrochemical Measurements. A conventional threeelectrode system was employed in all experiments. The enzyme electrode was used as the working electrode. A platinum wire electrode was applied to be the auxiliary electrode. The reference electrode was an $\mathrm{Ag} / \mathrm{AgCl}$ electrode. The CHI660E electrochemical workstation was used to perform all the electrochemical experiments.

\section{Results and Discussion}

3.1. Fluorescent Characterization of HRP-AuNCs. First, fluorescent HRP-AuNCs were synthesized. Under $365 \mathrm{~nm}$ UV light excitation, the prepared HRP-AuNC solution emitted intense red fluorescence at $650 \mathrm{~nm}$ and a weak peak at $450 \mathrm{~nm}$ (Figure 1). The HRP solution without AuNCs emitted no fluorescence. After adding $50 \mathrm{mM} \mathrm{H}_{2} \mathrm{O}_{2}$ in the HRPAuNC solution, the $650 \mathrm{~nm}$ peak reduced considerably, and the $450 \mathrm{~nm}$ peak increased considerably. The change in fluorescence intensity was due to changes in the surrounding microenvironment of AuNCs. Additionally, the results indicated that HRP after synthetic reaction remains active and enables the catalytic reaction to $\mathrm{H}_{2} \mathrm{O}_{2}$. The enzyme activity of HRP was also measured which decreases about $34.3 \%$ after reacting with $\mathrm{HAuCl}_{4}$.

3.2. Electrochemical Characterization of HRPAuNCs/MWCNTs/CFUMEs. Cyclic voltammograms of different modified electrodes are presented in Figure 2. A pair of small redox peaks appears in the cyclic voltammogram (CV) of the HRP/MWCNTs/CFUMEs (Figure 2(b)) and MWCNTs/CFUMEs (Figure 2(c)). The cathodic peak potential and the anodic peak potential were $-0.1 \mathrm{~V}$ and $0 \mathrm{~V}$, respectively. This pair of redox peaks is from the redox of carboxylic acid groups of MWCNTs immobilized on the surface of the electrode. Comparing with that of bare CFUME (Figure 2(f)), the background current was much larger due to the increased surface charge from MWCNTs [16]. The $\mathrm{CV}$ of HRP-AuNCs/MWCNTs/CFUMEs (Figure 2(a)) exhibits a pair of evident redox peaks, which were attributed to Fe(III)-to-Fe(II) conversion of the HRP. The cathodic and 


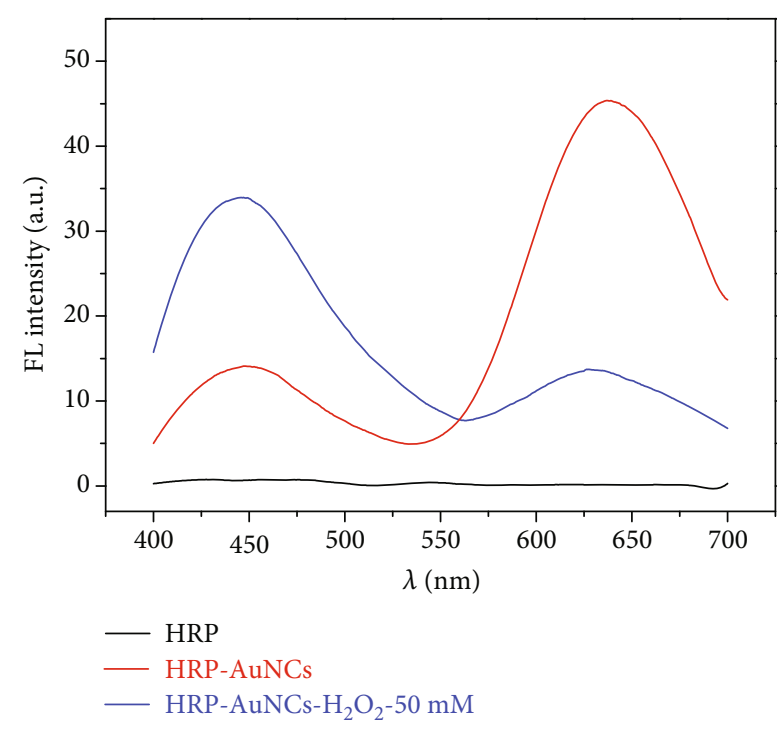

FIgURE 1: Fluorescence spectra of HRP (black line) and HRPAuNCs in the absence (red line) and presence (blue line) of $50 \mathrm{mM} \mathrm{H}_{2} \mathrm{O}_{2}$.

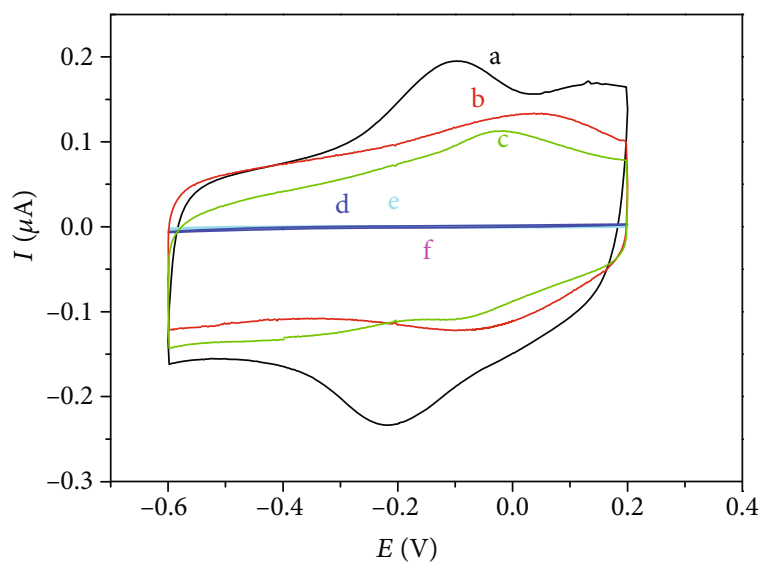

FIgure 2: Cyclic voltammograms of HRPAuNCs/MWCNTs/CFUMEs (a), HRP/MWCNTs/CFUMEs (b), MWCNTs/CFUMEs (c), HRP-AuNCs/CFUMEs (d), HRP/CFUMEs (e), and CFUME (f) in $0.01 \mathrm{M}$ deoxygenated PBS, pH 7.0, at a scan rate of $100 \mathrm{mV} / \mathrm{s}$.

anodic peak potentials were $-0.21 \mathrm{~V}$ and $-0.1 \mathrm{~V}$. The formal potential was calculated to be $-0.16 \mathrm{~V}$ by averaging two peak voltages. The potential difference was approximately $110 \mathrm{mV}$, which indicated a quasireversible process [17]. After 100 cyclic scans, the peak current was unchanged, which indicates that the modified film was very stable. HRP/MWCNTs/CFUMEs (Figure 2(b)) does not show a characteristic peak of HRP, which indicates that the AuNCs acting as the molecular electric wire can help to transfer the electrons between the active center of the enzyme and the electrode. HRP-AuNCs/CFUMEs (Figure 2(d)) did not show obvious redox peaks, and the current was much lower. This may be because that without the aid of the MWCNTs, the HRP-AuNCs could barely be immobilized on the surface of bare CFUMEs. MWCNTs could enlarge the interface area

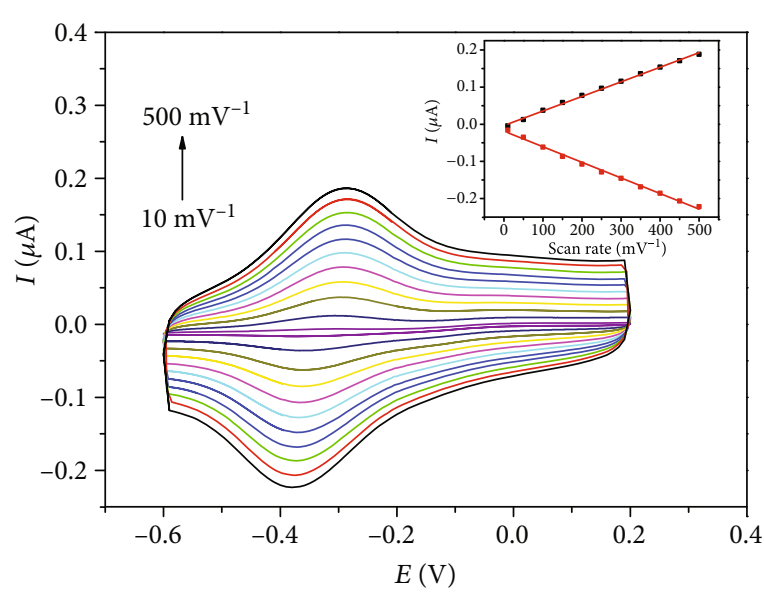

FIgURE 3: Cyclic voltammograms of HRPAuNCs/MWCNTs/CFUMEs in $0.01 \mathrm{M}$ pH 7.0 deoxygenated PBS at scan rates of $10,50,100,150,200,250,300,350,400,450$, and $500 \mathrm{mV} / \mathrm{s}$ (inset: plots of anodic and cathodic peak currents vs. scan rate).

and increase conductivity of the electrode. These characteristics greatly increase the direct electron conduction from the HRP-AuNCs to the surface of the electrode. Therefore, the current signals amplified are enlarged [18].

The effect of scanning rates on HRPAuNCs/MWCNTs/CFUMEs was investigated (Figure 3). With the increase of scan rates, the oxidation and reduction peak current increase linearly (inset plot in Figure 3). The results indicate that this is a typical surface-controlled electrochemical process. According to the peak area of HRPAuNCs/MWCNTs/CFUMEs in the cyclic voltammogram, the average surface coverage of HRP immobilized on the electrode was $5.15 \times 10^{-9} \mathrm{~mol} / \mathrm{cm}^{2}$. The theoretical monolayer coverage of HRP is $8.5 \times 10^{-12} \mathrm{~mol} / \mathrm{cm}^{2}$. The high surface coverage indicates that there were multilayers of HRP which were modified on the surface of the electrode and participated in the electron transfer process [19]. With the change in scan rate, the anodic and cathodic peak potentials were unchanged, which may be because of the rapid electron transfer process between the enzyme and electrode. Moreover, the results indicate that HRP was immobilized in a favorable microenvironment for promoting electron transfer.

3.3. Electrocatalytic Reduction of $\mathrm{H}_{2} \mathrm{O}_{2}$ on HRPAuNCs/MWCNTs/CFUMEs. The amperometric responses of different modified electrodes to $\mathrm{H}_{2} \mathrm{O}_{2}$ were compared (as shown in Supplementary Figure 3). The applied potential was chosen as $-0.1 \mathrm{~V}$. The low potential which was close to zero can improve the selectivity of sensors to $\mathrm{H}_{2} \mathrm{O}_{2}$ by reducing the reaction of interferences. The response of HRP-AuNCs/MWCNTs/CFUMEs was more than 30 times that of HRP/MWCNTs/CFUMEs, which indicates that the AuNCs acting as the molecular electric wire can help transfer electrons between the active center of the enzyme and the surface of the electrode. No response was present in the electrodes without HRP or MWCNTs. This result suggests that HRP-AuNCs/MWCNTs/CFUMEs are better suited for amperometric measurement. The results also 


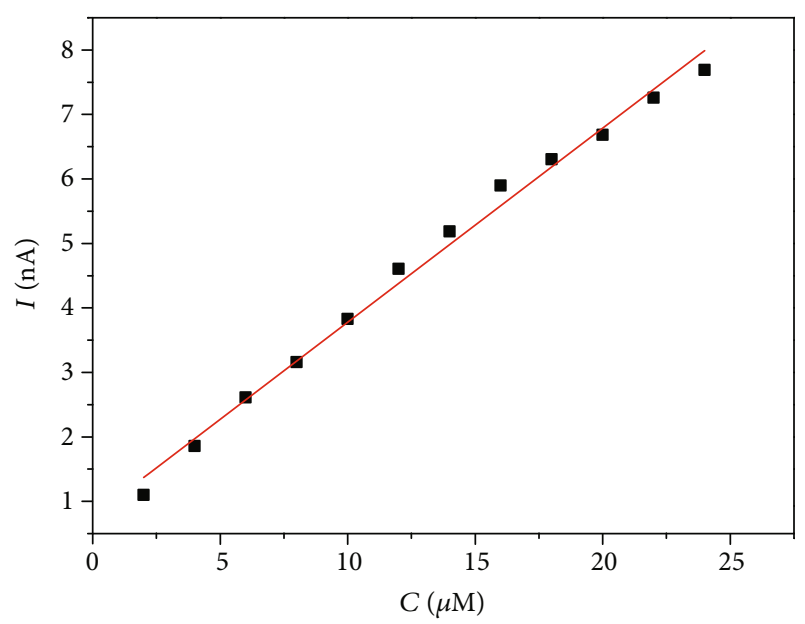

FIGURE 4: Calibration curve of the faradic current with respect to the concentration of $\mathrm{H}_{2} \mathrm{O}_{2}$ in deoxygenated 0.01 M PBS.

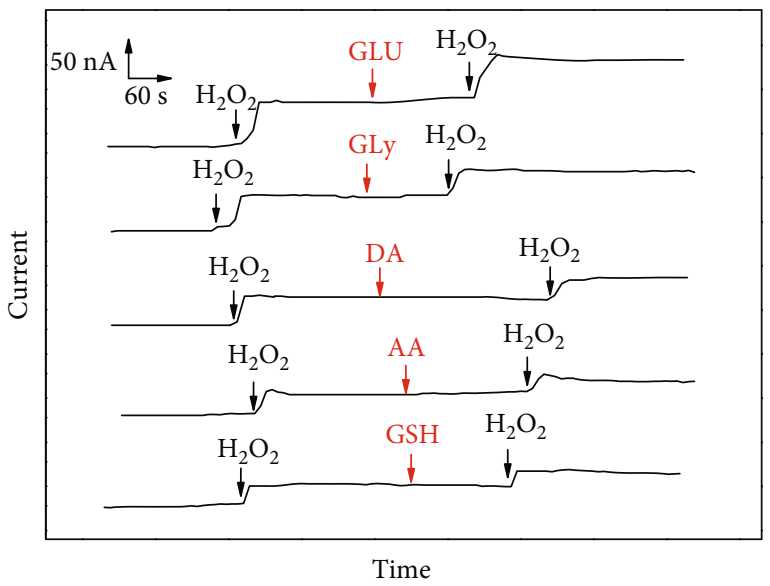

Figure 5: Amperometric response of the HRPAuNCs/MWCNTs/CFUMEs to $10 \mu \mathrm{M} \mathrm{H}_{2} \mathrm{O}_{2} ; 100 \mu \mathrm{M}$ GLU, Gly, DA, AA, or GSH; and $10 \mu \mathrm{M} \mathrm{H}_{2} \mathrm{O}_{2}$ in turn after subtracting the baseline.

indicate the high enzyme activity after the HRP-AuNC formation.

Figure 4 shows that the calibration curve of the amperometric response is linear in the range of $2 \mu \mathrm{M}$ to $24 \mu \mathrm{M}\left(R^{2}=0.991 ; p=1.2 e^{-7}\right)$, and the sensitivity is $3.0 \times$ $10^{-4} \mathrm{~A} / \mathrm{M}$. The detection limit of the biosensor was found to be $443 \mathrm{nM}$ at a signal-to-noise ratio of 3. According to the Lineweaver-Burk equation, the apparent MichaelisMenten constant (Km, app) was calculated to be $15.4 \mu \mathrm{M}$. The constant is a reflection of the enzymatic affinity and the ratio of microscopic kinetic constant. The $\mathrm{Km}$, app in this biosensor is much smaller than $1.35 \mathrm{mM}$ (HRP-SG/CNT/GC electrode) [20], $0.12 \mathrm{mM}$ (MB-HRP/NME/MWCNT/GC electrode), and $23.85 \mathrm{mM}$ (HRP/SGCCN/GC electrode) [21]), which indicate the higher biological affinity of immobilized HRP to $\mathrm{H}_{2} \mathrm{O}_{2}$.

The interference of common species was examined as shown in Figure 5. The applied potential was $-0.1 \mathrm{~V}$, which is lower than $+0.25 \mathrm{~V}$ by Okawa et al. [12]. This

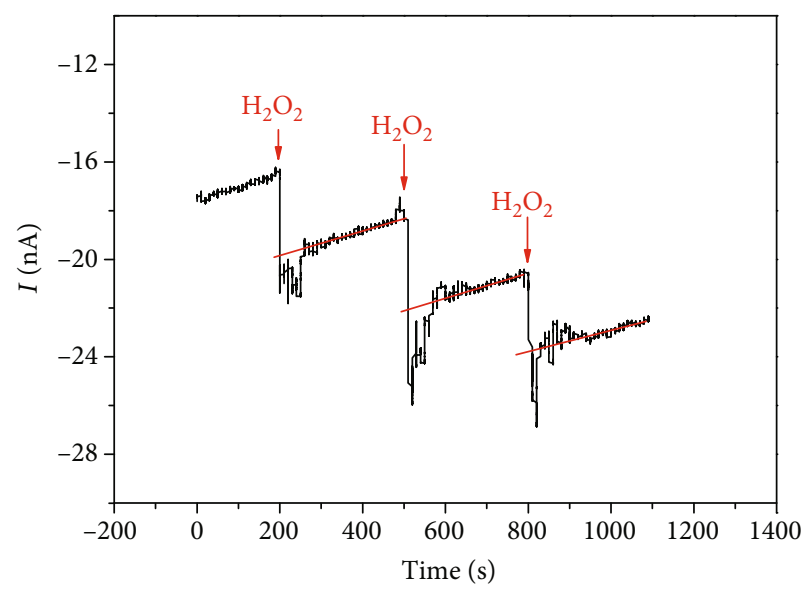

FIgURE 6: Amperometric responses of the HRPAuNC/MWCNT/CFUME electrode upon the addition of calf serum sample followed by successive addition of $10 \mu \mathrm{M} \mathrm{H}_{2} \mathrm{O}_{2}$ for three times in $10 \mathrm{ml} \mathrm{0.01} \mathrm{M} \mathrm{PBS}(\mathrm{pH}=7.1)$.

TABLE 1: Determination of $\mathrm{H}_{2} \mathrm{O}_{2}$ in calf serum sample.

\begin{tabular}{lccc}
\hline $\mathrm{H}_{2} \mathrm{O}_{2}$ spiked & $\begin{array}{c}\text { Concentration added } \\
C(\mu \mathrm{M})\end{array}$ & $\begin{array}{c}\mathrm{RSD} \\
(\%)\end{array}$ & $\begin{array}{c}\text { Mean recovery } \\
(\%)\end{array}$ \\
\hline 10 & 9.916 & 1.9 & 92.6 \\
10 & 9.912 & 1.8 & 88.5 \\
10 & 9.909 & 2.0 & 99.7 \\
\hline
\end{tabular}

low potential can effectively reduce possible interferences, thus resulting in high selectivity to $\mathrm{H}_{2} \mathrm{O}_{2}$. The amperometric response increased greatly after injection of $10 \mu \mathrm{M}$ $\mathrm{H}_{2} \mathrm{O}_{2}$. No change in current was observed after injecting 10-fold concentrations of glucose (GLU), glycine (Gly), dopamine (DA), ascorbic acid (AA), and glutathione (GSH). Moreover, the current change caused by $\mathrm{H}_{2} \mathrm{O}_{2}$ was not affected by these interfering species. These results validate that the HRP-AuNCs/MWCNTs/CFUMEs had a favorable anti-interference ability and were appropriate for in vivo measurement.

The reproducibility of the HRP-AuNCs/MWCNTs/CFUMEs was also investigated. The response to $10 \mu \mathrm{M} \mathrm{H}_{2} \mathrm{O}_{2}$ was measured and the relative standard deviation (RSD) is 5.5\% (as shown in Supplementary Figure 4).

3.4. Detection of $\mathrm{H}_{2} \mathrm{O}_{2}$ in Calf Serum. To test the practical applications of the $\mathrm{H}_{2} \mathrm{O}_{2}$ sensor, the concentration of $\mathrm{H}_{2} \mathrm{O}_{2}$ was detected in calf serum samples using the modified electrode by the widely used standard titration method $[22,23]$. The calf serum was diluted 10 times by PBS $(0.01 \mathrm{M}, p H=$ 7.0 ) and was predeoxygenated by purging ultrapure argon gas to avoid interference from oxygen. At intervals of $350 \mathrm{~s}$, a $\mathrm{H}_{2} \mathrm{O}_{2}$ standard concentration was injected into the diluted calf serum. With the injection of $\mathrm{H}_{2} \mathrm{O}_{2}$, quick and sensitive responses were observed, as shown in Figure 6. The concentration of $\mathrm{H}_{2} \mathrm{O}_{2}$ spiked each time was $10 \mu \mathrm{M}$. As shown in Table 1, the concentration of $\mathrm{H}_{2} \mathrm{O}_{2}$ in calf serum samples was calculated by the standard addition method [24]. The 
mean recovery of $\mathrm{H}_{2} \mathrm{O}_{2}$ in calf serum samples was $93.6 \%$, which validates that HRP-AuNCs/MWCNTs/CFUMEs have a potential application in $\mathrm{H}_{2} \mathrm{O}_{2}$ measurement of real samples.

\section{Conclusions}

In this study, an amperometric $\mathrm{H}_{2} \mathrm{O}_{2}$ sensor has been fabricated using HRP-AuNC- and MWCNT-modified CFUMEs. The carbon fiber ultramicroelectrode (CFUME) (diameter $7 \mu \mathrm{m}$ ) used in this research has much smaller dimension than indium-tin oxide- (ITO-) or fluoride-doped tin oxide- (FTO) coated glass plates [12], which can match the biological microenvironments such as cells or tissues with minimized perturbation or damage. Furthermore, the CFUME has good biocompatibility, easy fabrication, and good electron transfer properties, which make it an ideal tool for real-time in vivo measurement. Horseradish peroxidase (HRP) was modified by functionalized gold nanoclusters (AuNCs) via a biomineralization process to promote electron transfer. The $\mathrm{H}_{2} \mathrm{O}_{2}$ sensor was successfully applied to detect $\mathrm{H}_{2} \mathrm{O}_{2}$ levels in calf serum. The electrochemical data suggested that the gold nanoclusters acting as the molecular electric wire can help to transfer electrons between the active center of the enzyme and the electrode. Moreover, the enzyme conjugated by the AuNCs and being immobilized on MWCNT-coated CFUME can retain high biological activity. HRP-AuNCs were modified with the assistance of immobilized MWCNTs on the surface of the CFUME. The AuNCs facilitate electron transfer between the active center of HRP and CFUME. The characteristic immensely facilitates the detection limit and generates a satisfactory anti-interference ability. These features were especially preferred by in vivo sensing applications. The HRP-AuNCs/MWCNTs/CFUMEs were successfully applied to carry out measurement of $\mathrm{H}_{2} \mathrm{O}_{2}$ in the calf serum sample, and the results show that the test concentration is in close proximity to the real concentration spiked in the sample. This sensor is expected to monitor the level of $\mathrm{H}_{2} \mathrm{O}_{2}$ in vivo and facilitate research on the role of $\mathrm{H}_{2} \mathrm{O}_{2}$ in the life course.

\section{Data Availability}

The data used to support the findings of this study are included within the article.

\section{Conflicts of Interest}

The authors declare that they have no conflicts of interest.

\section{Acknowledgments}

This work was supported by the Natural Science Foundation of Henan Province (Grant nos. 172102310541 and 19A416007), the Natural Science Foundation of Hubei Province (nos. 2018CFB159 and 2016CFB262), the Natural Science Foundation of Xinxiang (CXGG17005), and the support project for the Disciplinary Group of Psychology and Neuroscience, Xinxiang Medical University (2016PNKFKT-24). We would like to thank Editage [http://www .editage.cn] for English language editing.

\section{Supplementary Materials}

Supplementary Figure 1: TEM image of HRP-AuNCs. Supplementary Figure 2: cyclic voltammograms of the HRPAuNCs/MWCNTs/CFUMEs (A), HRP/MWCNTs/CFUMEs (B), MWCNTs/CFUMEs (C), HRP-AuNCs/CFUMEs (D), HRP/CFUME (E), and CFUME (F) in 0.01 M pH 7.0 deoxygenated PBS in the absence of $\mathrm{H}_{2} \mathrm{O}_{2}$ (a) and presence of $0.01 \mathrm{mM}$ (b) and $0.03 \mathrm{mM}$ (c). Scan rate $=100 \mathrm{mV} / \mathrm{s}$. Supplementary Figure 3: amperometric response of the HRPAuNCs/MWCNTs/CFUMEs (a), HRP/MWCNTs/CFUMEs (b), MWCNTs/CFUMEs (c), HRP-AuNCs/CFUMEs (d), HRP/CFUME (e), and CFUME (f) in 0.01 M PBS containing $10 \mu \mathrm{M} \quad \mathrm{H}_{2} \mathrm{O}_{2}$. Supplementary Figure 4: amperometric response of the HRP-AuNCs/MWCNTs/CFUMEs to $10 \mu \mathrm{M} \mathrm{H}_{2} \mathrm{O}_{2}$ in $0.01 \mathrm{M}$ PBS. (Supplementary Materials)

\section{References}

[1] P. Bollella and L. Gorton, "Enzyme based amperometric biosensors," Current Opinion in Electrochemistry, vol. 10, pp. 157-173, 2018.

[2] C.-X. Lei, S.-Q. Hu, N. Gao, G.-L. Shen, and R.-Q. Yu, “An amperometric hydrogen peroxide biosensor based on immobilizing horseradish peroxidase to a nano-Au monolayer supported by sol-gel derived carbon ceramic electrode," Bioelectrochemistry, vol. 65, no. 1, pp. 33-39, 2004.

[3] J. I. Reyes-De-Corcuera, H. E. Olstad, and R. García-Torres, "Stability and stabilization of enzyme biosensors: the key to successful application and commercialization," Annual Review of Food Science and Technology, vol. 9, no. 1, pp. 293-322, 2018.

[4] P. Das, M. Das, S. R. Chinnadayyala, I. M. Singha, and P. Goswami, "Recent advances on developing 3rd generation enzyme electrode for biosensor applications," Biosensors and Bioelectronics, vol. 79, pp. 386-397, 2016.

[5] R. A. Blaik, E. Lan, Y. Huang, and B. Dunn, "Gold-coated M13 bacteriophage as a template for glucose oxidase biofuel cells with direct electron transfer," ACS Nano, vol. 10, no. 1, pp. 324-332, 2015.

[6] G. Rocchitta, A. Spanu, S. Babudieri et al., "Enzyme biosensors for biomedical applications: strategies for safeguarding analytical performances in biological fluids," Sensors, vol. 16, no. 6, p. 780, 2016.

[7] M. Hatada, N. Loew, Y. Inose-Takahashi et al., "Development of a glucose sensor employing quick and easy modification method with mediator for altering electron acceptor preference," Bioelectrochemistry, vol. 121, pp. 185-190, 2018.

[8] B. Liang, X. Guo, L. Fang et al., "Study of direct electron transfer and enzyme activity of glucose oxidase on graphene surface," Electrochemistry Communications, vol. 50, pp. 1-5, 2015.

[9] P. Mehrotra, "Biosensors and their applications - a review," Journal of Oral Biology and Craniofacial Research, vol. 6, no. 2, pp. 153-159, 2016.

[10] X. Li, M. Yu, Z. Chen, X. Lin, and Q. Wu, “A sensor for detection of carcinoembryonic antigen based on the polyaniline-Au nanoparticles and gap-based interdigitated electrode," Sensors and Actuators B: Chemical, vol. 239, pp. 874-882, 2017.

[11] I. Taurino, G. Sanzò, R. Antiochia et al., "Recent advances in third generation biosensors based on $\mathrm{Au}$ and $\mathrm{Pt}$ 
nanostructured electrodes," TrAC Trends in Analytical Chemistry, vol. 79, pp. 151-159, 2016.

[12] Y. Okawa, N. Yokoyama, Y. Sakai, and F. Shiba, "Direct electron transfer biosensor for hydrogen peroxide carrying nanocomplex composed of horseradish peroxidase and $\mathrm{Au}-$ nanoparticle - characterization and application to bienzyme systems," Analytical Chemistry Research, vol. 5, pp. 1-8, 2015.

[13] F. Wen, Y. Dong, L. Feng, S. Wang, S. Zhang, and X. Zhang, "Horseradish peroxidase functionalized fluorescent gold nanoclusters for hydrogen peroxide sensing," Analytical Chemistry, vol. 83, no. 4, pp. 1193-1196, 2011.

[14] Q.-Q. Ren, J. Wu, W.-C. Zhang et al., "Real-time in vitro detection of cellular $\mathrm{H}_{2} \mathrm{O}_{2}$ under camptothecin stress using horseradish peroxidase, ionic liquid, and carbon nanotubemodified carbon fiber ultramicroelectrode," Sensors and Actuators B: Chemical, vol. 245, pp. 615-621, 2017.

[15] Q. Q. Ren, X. J. Yuan, X. R. Huang, W. Wen, Y. D. Zhao, and W. Chen, "In vivo monitoring of oxidative burst on aloe under salinity stress using hemoglobin and single-walled carbon nanotubes modified carbon fiber ultramicroelectrode," Biosensors \& Bioelectronics, vol. 50, pp. 318-324, 2013.

[16] H. Luo, Z. Shi, N. Li, Z. Gu, and Q. Zhuang, "Investigation of the electrochemical and electrocatalytic behavior of singlewall carbon nanotube film on a glassy carbon electrode," Analytical Chemistry, vol. 73, no. 5, pp. 915-920, 2001.

[17] H. A. Rafiee-Pour, M. Hamadanian, and S. K. Koushali, "Nanocrystalline $\mathrm{TiO}_{2}$ films containing sulfur and gold: synthesis, characterization and application to immobilize and direct electrochemistry of cytochrome c," Applied Surface Science, vol. 363, pp. 604-612, 2016.

[18] Y. Yan, W. Zheng, M. Zhang, L. Wang, L. Su, and L. Mao, "Bioelectrochemically functional nanohybrids through coassembling of proteins and surfactants onto carbon nanotubes: facilitated electron transfer of assembled proteins with enhanced faradic response," Langmuir, vol. 21, no. 14, pp. 6560-6566, 2005.

[19] G. Liu and J. J. Gooding, “An interface comprising molecular wires and poly(ethylene glycol) spacer units self-assembled on carbon electrodes for studies of protein electrochemistry," Langmuir, vol. 22, no. 17, pp. 7421-7430, 2006.

[20] J. Wang, M. Gu, J. Di, Y. Gao, Y. Wu, and Y. Tu, “A carbon nanotube/silica sol-gel architecture for immobilization of horseradish peroxidase for electrochemical biosensor," Bioprocess and Biosystems Engineering, vol. 30, no. 4, pp. 289-296, 2007.

[21] H. Chen and S. Dong, "Direct electrochemistry and electrocatalysis of horseradish peroxidase immobilized in solgel-derived ceramic-carbon nanotube nanocomposite film," Biosensors \& Bioelectronics, vol. 22, no. 8, pp. 1811-1815, 2007.

[22] J. Ju and W. Chen, "In situ growth of surfactant-free gold nanoparticles on nitrogen-doped graphene quantum dots for electrochemical detection of hydrogen peroxide in biological environments," Analytical Chemistry, vol. 87, no. 3, pp. 1903-1910, 2015.
[23] J. Bai and X. Jiang, "A facile one-pot synthesis of copper sulfide-decorated reduced graphene oxide composites for enhanced detecting of $\mathrm{H}_{2} \mathrm{O}_{2}$ in biological environments," Analytical Chemistry, vol. 85, no. 17, pp. 8095-8101, 2013.

[24] B. Thirumalraj, D.-H. Zhao, S.-M. Chen, and S. Palanisamy, "Non-enzymatic amperometric detection of hydrogen peroxide in human blood serum samples using a modified silver nanowire electrode," Journal of Colloid and Interface Science, vol. 470, pp. 117-122, 2016. 